\title{
Synthesis of (+)-boronolide and (+)-deacetylboronolide using Pd-catalyzed carbonylation and lactonization
}

Yuji Kurogome, ${ }^{\mathrm{a}}$ Yasunao Hattori, ${ }^{\mathrm{b}}$ and Hidefumi Makabe*a

${ }^{\mathrm{a}}$ Graduate School of Agriculture, Sciences of Functional Foods, Shinshu University,

8304 Minami-minowa Kami-ina, Nagano, 399-4598, Japan

${ }^{\mathrm{b}}$ Department of Medicinal Chemistry, Kyoto Pharmaceutical University, Yamashina-ku, Kyoto 607-8412, Japan

*Corresponding author. Tel. +81 26577 1630; fax +81 26577 1700; e-mail: makabeh@ shinshu-u.ac.jp

Abstract: (+)-Boronolide and (+)-deacetylboronolide were synthesized using Pd-catalyzed CO insertion and lactonization as the key step. As to the ${ }^{13} \mathrm{C}$ NMR data of (+)-deacetylboronolide, the assignment at C-6 position should be revised.

Key words: natural products, lactones, asymmetric synthesis, total synthesis, carbonylation

(+)-Boronolide (1) was isolated Tetradenia fruticosa Benth and Tetradenia barbera (N. E. Br.) Codd, respectively. ${ }^{1,2}$ The leaves of Tetradenia barbera was used as a folk medicine in Madagascar and south Africa. ${ }^{3}$ (+)-Deacetylboronolide (2) was isolated by Luc Van Puyvelde and co-workers from Tetradenia riparia (Hochst) N. E. Br. (Labiatae). ${ }^{4}$ Tetradenolide (3), which is a related compounds of $\mathbf{1}$ and $\mathbf{2}$, was also isolated from the same plant. ${ }^{5}$ As to the biological activity of boronolides, anti-malarial activity was reported (Figure 1). ${ }^{3,4}$
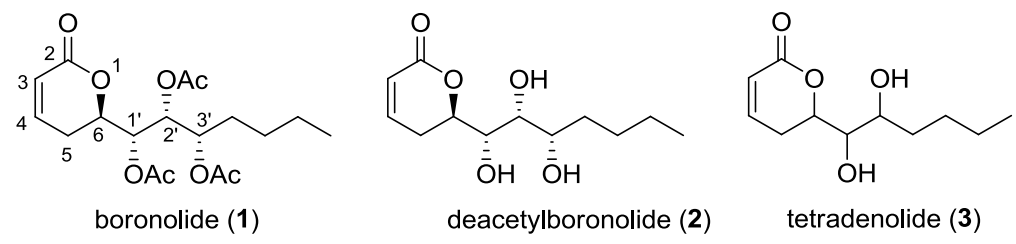

Figure 1. The structures of boronolide (1) and deacetylboronolide (2).

Due to significant biological activity as well as unique structure, boronolide and its related compounds attracted much attention of many synthetic chemists. ${ }^{6 a-m}$ In the typical examples of asymmetric syntheses of boronolide, Sharpless asymmetric dihydroxylation, ${ }^{6 \mathrm{~b}}$ asymmetric aldol reaction, ${ }^{6 \mathrm{~d}, 6 \mathrm{e}}$ and chiral pool approach ${ }^{6 \mathrm{a}, 6 \mathrm{~d}, 6 \mathrm{f}}$ were used to construct four chiral centers. The typical example of preparation of $\alpha, \beta$-unsaturated $\delta$-lactone was done using elimination of selenoxide ${ }^{6 a, 6 b, 6 f}$ or ring-closing olefin metathesis. ${ }^{6 e}$ To synthesize $\alpha, \beta$-unsaturated $\delta$-lactones, $\mathrm{Pd}$ catalyzed $\mathrm{CO}$ insertion and cyclization of $(Z)$-alkenyl halide is one of the most useful tools. ${ }^{7}$ In this paper, we wish to describe concise synthesis of (+)-boronolide (1) and (+)-deacetylboronolide (2) using Pd-catalyzed 
carbonylation. Scheme 1 outlines our synthetic strategy of (+)-boronolide (1) and (+)-deacetylboronolide (2). The key step is Pd-catalyzed CO insertion and cyclization to form $\delta$-lactone 4. ${ }^{7,8}$ The cyclization precursor 5 can be prepared from terminal alkyne $\mathbf{6}$. The alkyne $\mathbf{6}$ can be synthesized from 7 which could be prepared from Dmannitol using Singh's procedure. ${ }^{6 f}$

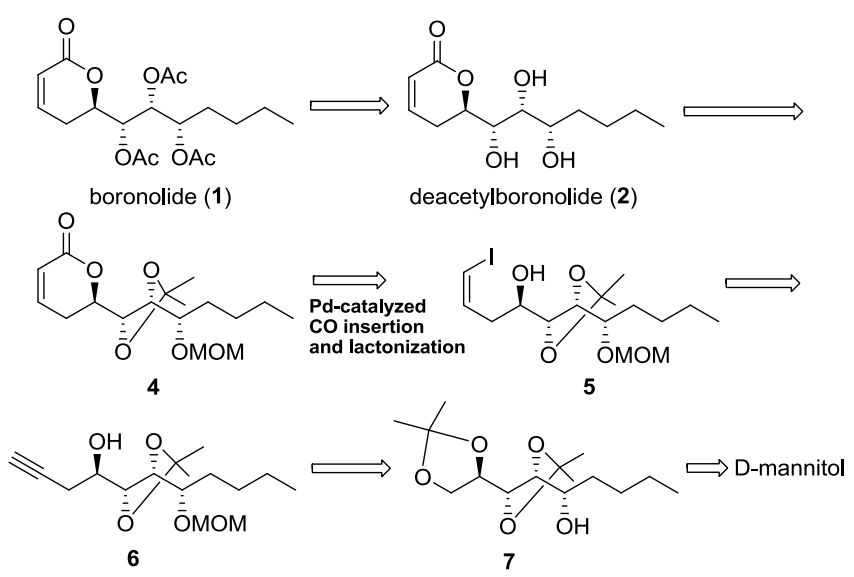

Scheme 1. Synthetic strategy of boronolide (1) and deacetylboronolide (2).

Compound 7 was constructed as Singh and co-workers reported with slight modification. ${ }^{6 f}$ The secondary hydroxy group of $\mathbf{7}$ was protected as MOM ether to afford $\mathbf{8}$. Selective deprotection of the terminal acetonide of $\mathbf{8}$ was achieved using copper (II) chloride hydrate to give diol $9 .{ }^{6 f}$ Conversion of the diol 9 to the terminal epoxide 10 was attained via introducing triisopropylbenzenesulfonyl (Tris) group at primary hydroxy group followed by treatment with $\mathrm{NaH}$. The epoxide $\mathbf{1 0}$ was treated with lithium acetylide, an ethylenediamine complex in DMSO afforded terminal acetylene 6 . Introduction of iodine at terminal acetylene was done by treatment with $\mathrm{I}_{2}$ in the presence of $\mathrm{NaOMe}$ to afford 11. Diimide reduction of $\mathbf{1 1}$ with $\mathrm{NsNHNH}_{2}$ in the presence of $\mathrm{Et}_{3} \mathrm{~N}$ gave $Z$-alkenyl iodide 5. ${ }^{9}$ The geometry of $Z$-alkenyl iodide 5 was confirmed by coupling constant value $(J=8.0 \mathrm{~Hz})$ of olefinic protons in ${ }^{1} \mathrm{H}$ NMR. The iodide 5 was subjected to Pd-catalyzed CO insertion and cyclization. As shown in Table 1 , using $\mathrm{K}_{2} \mathrm{CO}_{3}$ as a base and hydrazine hydrate as an additive was effective in this reaction as Hoye and coworker reported (Table 1). ${ }^{10}$

Table 1. Pd-catalyzed CO insertion and cyclization of vinyl iodide 5. ${ }^{\mathrm{a}}$

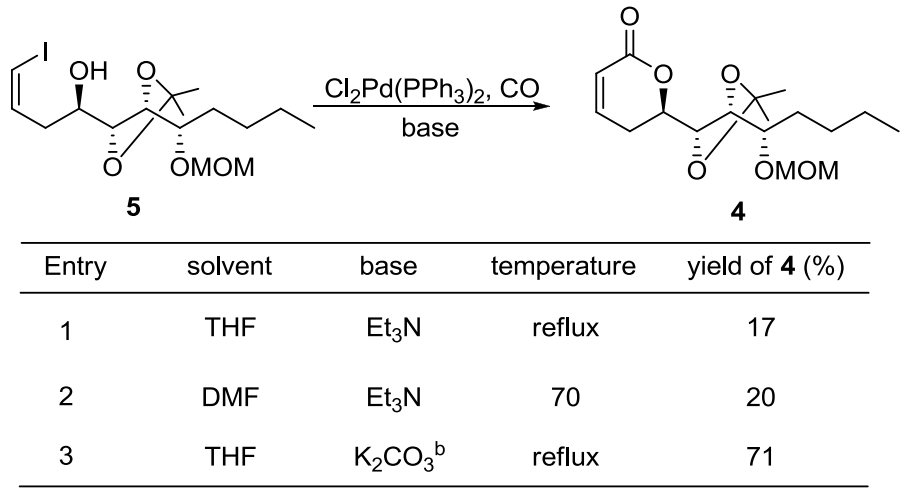

aThe reaction time was $24 \mathrm{~h} .{ }^{\mathrm{b}}$ One drop of hydrazine was added. 
Deprotection of both of the acetonide and MOM groups using Dowex 50w gave (+)-deacetylboronolide (2). The physicochemical data and spectral data except ${ }^{13} \mathrm{C}$ NMR of 2 were consistent with those of the reported values. ${ }^{[2]}$ As to the ${ }^{13} \mathrm{C}$ NMR data at C-6 carbon, Rivett and co-worker who isolated 2 reported that this signal was overlapped with that of a solvent residual peak of $\mathrm{CDCl}_{3}(76.74 \mathrm{ppm}){ }^{2}{ }^{2}(+)$-Deacetylboronolide (2) was synthesized by Trost and Singh independently and they also reported the existence of peak at $76.74 \mathrm{ppm}^{6 \mathrm{~d}, 6 \mathrm{f}}$ However, when we measured HMQC NMR, we found that the chemical shift of C-6 carbon was 77.15 ppm and C-1' and C-2' carbons were overlapped at 74.24 ppm (shown in supporting information). Moreover we found that the peak at $76.74 \mathrm{ppm}$ did not exist. The assignment at C-6, C-1' and C-2' carbons should be revised (Figure 2). We also measured ${ }^{13} \mathrm{C}$ NMR using $\mathrm{CD}_{3} \mathrm{CN}$ as deuterated solvent, overlapped C-1' and C-2' signals separated and four oxymethine carbons were clearly observed (shown in supporting information). Next, treatment of 2 with $\mathrm{Ac}_{2} \mathrm{O}$ in pyridine afforded (+)-boronolide (1) in good yield. The physical and spectral data of $\mathbf{1}$ and $\mathbf{2}$ were consistent with those of the reported values (Scheme 2).

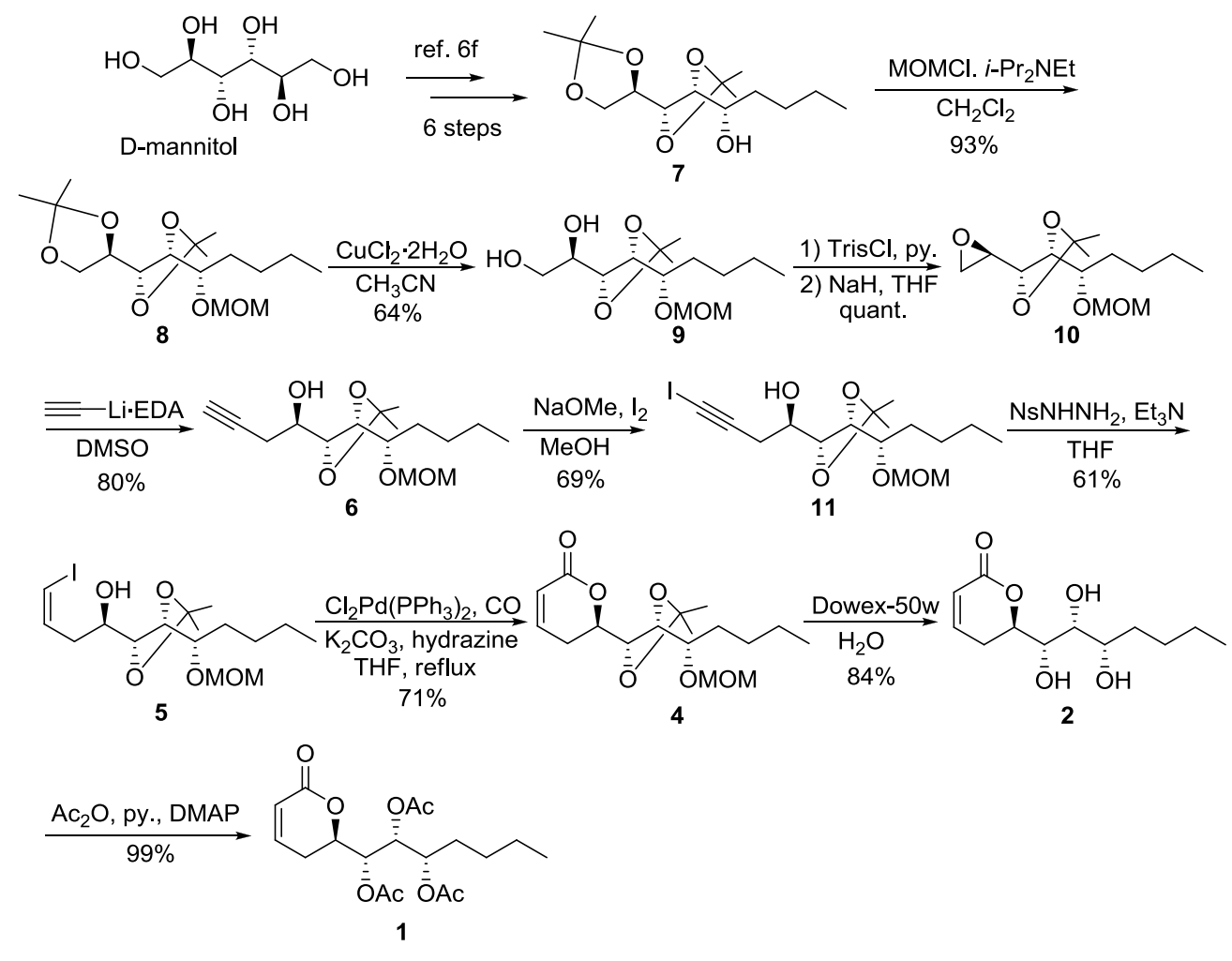

Scheme 2. Syntheis of boronolide (1) and deacetylboronolide (2).
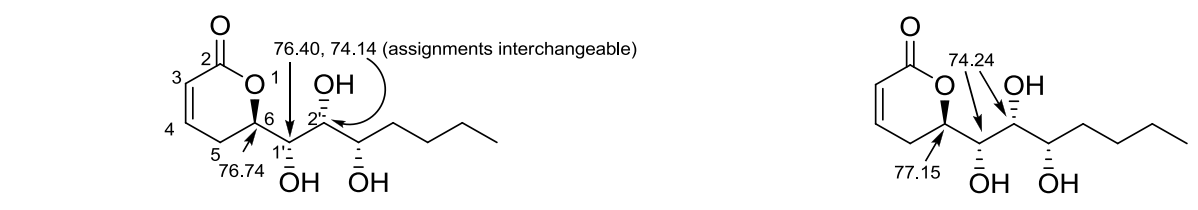

reported assignment at C-6, C-1' and C-2' positions ${ }^{2}$

revised assignment at $\mathrm{C}-6, \mathrm{C}-1$ ' and $\mathrm{C}-\mathrm{2}^{\prime}$ positions

Figure 2. Assignment of the ${ }^{13} \mathrm{C}$ NMR at C-6 carbon of deacetylboronolide (2) by HMQC experiment. 
In conclusion, we have accomplished the total synthesis of (+)-boronolide (1) and (+)-deacetylboronolide (2) using Pd-catalyzed carbonylation and lactonization strategy. This study will be adopted for the synthesis of natural products which contain an $\alpha, \beta$-unsaturated lactone rings.

\section{Acknowledgements}

This work was supported by JSPS KAKENHI Grant Number 24580160 to H. M.

\section{References and notes}

1. Franca, N. C.; Polonsky, J. C. R. Hebd. Seances, Acad. Sci., Ser. C. 1971, 273, 439.

2. Davies-Coleman, M. T.; Rivett, D. E. A. Phytochemistry 1987, 26, 3047.

3. Watt, J. M.; Brandwijk, M. G. B. The Medicinal and Poisonous Plants of Southern and Eastern Africa, Livingston: Edinburgh, 1962, p516.

4. (a) Van Puyvelde, L.; Dube, S.; Uwimana, E.; Uwera, C.; Domisse, R. A.; Esmans, E. L.; Van Schoor, O.; Vlietinck, A. Phytochemistry 1979, 18, 1215. (b) Van Puyvelde, L.; De Kimpe, N.; Dube, S.; Chagnon-Dube, M.; Boily, Y.; Borremans, F.; Schamp, N.; Anteunis, M. J. O. Phytochemistry 1981, 20, 2753.

5. Van Puyvelde, L.; De Kimpe, N. Phytochemistry 1998, 49, 1157.

6. (a) Nagano, H.; Yasui, H. Chem. Lett. 1992, 1045. (b) Honda, T.; Horiuchi, S.; Mizutani, H.; Kanai, K. J. Org. Chem. 1996, 61, 4944. (c) Ghosh, A. K.; Bilcer, G. Tetrahedron Lett. 2000, 41, 1003. (d) Trost, B. M.; Yeh, V. S. C. Org. Lett. 2002, 4, 3513. (e) Carda, M.; Rodoríguez, S.; Segovia, B.; Marco, J. A. J. Org. Chem. 2002, 67, 6560. (f) Chandrasekhar, M.; Chandra, K. L.; Singh, V. K. J. Org. Chem. 2003, 68, 4039. (g) Hu, S. -G.; Hu, T. -S.; Wu, Y. -L. Org. Biomol. Chem. 2004, 2, 2305. (h) Naidu, S. V.; Gupta, P.; Kumar, P. Tetrahedron Lett. 2005, 46, 2129. (i) Boruwa, J.; Barua, N. C. Tetrahedron 2006, 62, 1193. (j) Kumar, P.; Naidu, S. V. J. Org. Chem. 2006, 71, 3935. (k) Prasad, K. R.; Anbarasan, P. Tetrahedron: Asymmetry 2006, 17, 1146. (l) Raghavan, S.; Krishnaiah, V. Tetrahedron Lett. 2006, 47, 7611. (m) Yamauchi, S. ; Isozaki, Y.; Nishimura, Y.; Tsuda, H.; Nishiwaki, T.; Shuto, Y. Biosci. Biotechnol. Biochem. 2012, 76, 1708. (n) Reddy, B. V. S.; Reddy, V. V.; Praneeth, K. Tetrahedron Lett. 2014, 55, 1398.

7. (a) Farina, V.; Erikson, M. Handbook of Organopalladium Chemistry for Organic Synthesis, Wiley-VCH, Edited by E. Negishi, 2002, 2351-2375. (b) Cowell, A.; Stille, J. K. Tetrahedron Lett. 1979, 20, 133. (c) Cowell, A.; Stille, J. K. J. Am. Chem. Soc. 1980, 102, 4193.

8. Makabe, H.; Okajima, M.; Konno, H.; Kamo, T.; Hirota, M. Biosci. Biotechnol. Biochem. 2003, 67, 2658.

9. Adachi, Y.; Kamei, N.; Yokoshima, S.; Fukuyama, T. Org. Lett. 2011, 13, 4446.

10. Hoye, T. R.; Ye, Z. J. Am. Chem. Soc. 1996, 118, 1801. 